\section{The BTS and our 25th anniversary}

\section{Sheila Edwards}

\section{An organisation "fit for purpose"}

A the British Thoracic Society (BTS) comes to the end of its 25th anniversary year, several articles in this issue of Thorax have been commissioned to provide accounts of some of the important developments in respiratory medicine that have impacted on practice.

As well as the developments described in these articles, it is a suitable time to reflect on the changes that have taken place in the management and governance of the Society's affairs. These have provided a strong frame, a sturdy heart and a healthy set of bellows to fuel the drive and enthusiasm of all those colleagues over the last 25 years who have contributed to the Society's achievements. There have been several key events since Dr Martin MacNicol and Dr Harry Gribbin led a highly significant "think tank" in the early 1990s. This gave shape and structure to the Society's constitution and set up the Standing Committee structure which has remained in broadly similar format until the present day.

In 1998 a management review proposed by the Society's auditors resulted in clearer definition of the Trusteeship of the Society and the establishment of a more effective head office, with the appointment of the Society's first Chief Executive. The Charity Commission agreed to the necessary changes in the Memorandum and Articles of Association and therefore the elected Council became an advisory body for the Executive Committee, which became the Board of Trustees (ie, the Chairs of Standing Committees and Honorary Officers). A more recent change was agreed in 2006, which enabled the appointment of up to three Trustees who have no affiliation with a Standing Committee but who bring specific skills and experience as and when required (such as the recent appointment of a lay member).

The Society has for many years been a broad church, and there is a genuine commitment to inclusivity and team working across all levels. A significant change in the way in which interested members could be involved in the governance of the Society was introduced while Dr Jim Catterall was Honorary Secretary. His influential "democratisation" paper in 1999 still holds sway today-there is an annual call for volunteers for Committees in the summer each year, and we also encourage the participation of representatives of a number of allied professional organisations on Committees and Guideline Groups.

Those who were present to hear Professor Stephen Holgate's Presidential address at the December 2006 Winter Meeting heard him speak with passion and eloquence about the "Big Tent" - the need to continue to work towards the goal of bringing the voices of all respiratory health professionals and patients under one powerful umbrella. This pulled together several themes which had been actively pursued within the Society for several years, and work has continued in the past year with a number of organisations to provide practical and other support towards this goal. BTS has provided secretariat and other assistance to the Association of Respiratory Nurse Specialists since January 2006; is about to provide membership and other administrative support to the Association of Chartered Physiotherapists in Respiratory Care (ACPRC); has established a very important committee with primary care colleagues to look at maintaining standards of care across traditional boundaries as care moves into the community (IMPRESS); and is delighted to have been the catalyst and support mechanism for the development of the British Associations of Stop Smoking Practitioners (BASSP). This was launched at the House of Commons in July 2007 with a formal reception sponsored by its Patron, Kevin Barron MP.

All of the Society's activities are dedicated to improving standards of patient care. We must ensure that the Society's policies and recommendations are represented to policymakers and regional and local health providers as well as to our members. As we move into the new year, plans are well in hand to ensure that the Society has in place a leaner and more responsive structure with effective communication channels in place. The system of Specialist Advisory Groups, more strategic links with national and regional Thoracic Societies, plans for a more effective website, the ability to gather meaningful and targeted data about services, a streamlined and reformed Committee structure, a revised strategic planning cycle, and a newly-expanded head office team should all see the Society in good shape for the next 25 years, as the challenges from the external environment require more nimble responses.

Governance, management and communications issues are not the basis of heated or enthusiastic discussion over refreshments breaks during the Winter Meeting or at clinic team meetings. The best way to make sure that this happy state continues is for Trustees and others to continue to work together on our core activities and projects but remembering, from time to time, to review the Society's structures, to ensure that they always remain "fit for purpose".

Thorax 2007;62:1019.

doi: 10.1136/thx.2007.091116

Correspondence to: Sheila Edwards, British Thoracic Society, 17 Doughty Street, London WC1N 2PL, UK; sheila.edwards@brit-thoracic. org.uk

in the developed world and falling rates in the developing world. Some perceptive individuals were sounding the warning bells, but most pundits would have been profoundly wrong. They would have been closest to the mark if they had simply summed up their prediction of the position 25 years later, in 2007, as "Much the same, really-except where it's much worse."

Predictions about TB are particularly fraught with difficulty because the impact of factors beyond the control of clinicians, researchers and the pharmaceutical industry is far greater with TB than it is 